\title{
Shaking Table Experimental Researches Aimed at the Protection of Structures Subject to Dynamic Loading
}

\author{
Alessandro Baratta ${ }^{1}$, Ileana Corbi ${ }^{1}$, Ottavia Corbi ${ }^{*},{ }^{1}$, Rui Carneiro Barros ${ }^{*}, 2$ and Rogério Bairrão ${ }^{*}, 3$ \\ ${ }^{1}$ Department Structural Engineering, University of Naples Federico, Italy; ${ }^{2}$ Department Civil Engineering, University of \\ Porto, Portugal; ${ }^{3}$ National Laboratory of Civil Engineering, Portugal
}

\begin{abstract}
This paper provides an overview on some experimental activities developed by the authors, that represent a research group from European countries which has been cooperating for the last few years on common theoretical and laboratory activities, within the framework of some European or National research projects.

Highlights are presented in the paper focusing on experimental researches including the design, set up and testing of different control devices, executed on shaking table facilities and equipments available at the Universities of Naples, Porto and Lisbon.
\end{abstract}

Keywords: Shaking table, Experimental testing, Laboratory, Control devices, Dynamic excitation.

\section{CONTROL DEVICES FOR MITIGATING SEISMIC EFFECTS: EXPERIMENTAL INVESTIGATIONS}

Most natural disasters - earthquakes, volcanic eruptions, floods, tidal waves, storms, landslides or fires - occur without warning, causing significant damage to mankind not only in terms of loss of human life, but also diminishing the human quality of life in view of additional environmental devastation and economic losses.

The European Commission has not neglected the threat of natural disasters in Europe, despite its favourable climatic and geographic conditions. In fact, throughout the different framework programs, the European Commission sponsored dozens of research and development projects addressing several topics within the natural disasters thematic. These multidisciplinary projects involving multinational cooperation have promoted innovation and the development of creative skills, so important for the education and training of future generations of young Europeans.

Earthquakes are undoubtedly the most deadly natural disasters in the world, as well as the ones that can cause a wider variability of devastations by increasing the risk of damage to social, industrial and economic infrastructures. Extensive human suffering, in the order of tens of thousands of injuries and hundreds of thousands of homeless, resulted from earthquakes; in addition, the economic devastation was tremendous, due to the damaged infrastructure both in residential buildings and industrial facilities, affected commerce and destruction or heavy deterioration of vulnerable lifelines infrastructure and civil structures.

*Address correspondence to these authors at the Department Structural Engineering, University of Naples Federico II, Italy;

Tel/Fax: +39081 7683719; E-mail: ottavia.corbi@unina.it

Department Civil Engineering, University of Porto; + 22508 1814;

Fax: + 22508 1835; E-mail: rcb@fe.up.pt

National Laboratory of Civil Engineering; Tel: + +351 218443 823;

Fax: +351 218443 011; E-mail: bairrao@lnec.pt
Actually it is of great interest the possibility of actuating a large [1], medium and small scale risk prevention, of performing forecasts about catastrophic events such as seismic actions [2, 3], of equipping existing structures with devices able to effectively counteract dynamic vibrations [4-29] and give estimates and methods for the vulnerability of existing structures [30, 31].

In the last decades research on structural vibration control devices for buildings and bridges has been intensified to reply to construction market needs that demand more effective systems to decrease the damage caused by seismic and wind loading. This orientation is also the result of a public necessity to guarantee the serviceability of construction lifelines throughout and after the occurrence of a moderate or severe seismic event.

Control of structural vibrations induced by earthquake or wind can be approached by various methods such as modifying stiffness, damping, or shape, and by providing passive or active counter forces, as well as realizing semi-active devices by making recourse to special smart materials. To date, some methods of structural control based on the use of various active, semi-active, passive and hybrid control schemes have been used successfully and offer great promises. Nevertheless problems to be faced in structural control implementation are very complex and require the involvement of multidisciplinary teams. Advanced numerical tools need to be developed in order to perform preliminary analysis and to improve experimental facilities to validate different control methodologies and devices.

There are a few state-of-the-art papers on structural control, which provide a good overview of different structural control strategies developed and implemented in practice. They include state-of-the-art review on base isolation of structures by Kelly [4] and by Jangid and Datta [5]. On active structural control, the state-of-the-art paper by Soong [6] provide a comprehensive overview of different active struc- 
tural control systems. A relatively recent comprehensive review on structural control is presented by Housner et al. [7], and a state-of-the-art review on semi-active control is recently presented by Symans and Constantinou [8]. A updated brief state-of-the-art review on response-triggered structural control system was presented by Datta [9].

Full-scale implementation of active control systems have been accomplished in several structures, however, cost effectiveness and reliability considerations have limited their wide spread acceptance and pushed towards the adoption of semi-active systems that, because of their mechanical simplicity, low power requirements, and large, controllable force capacity, semi-active systems provide an attractive alternative to active and hybrid control systems for structural vibration reduction. A state of art on semi-active structural control and its implementation in full-scale structures can be referred to by Spencer and Nagarajaiah [10].

In the last years the authors of the paper have contributed to the structural control research, within some European and National research projects, by developing some analytical and numerical research, and laboratory experimentations, which represent a significant contribution in the sense that this allows to further improve control methods and to validate the performance of new structural systems, but also to consider strategies more suitable for the protection of the architectural heritage.

Major outcomes of researches have been achieved thanks to the availability of shaking table testing machines, that have allowed to execute a number of experimental investigations, that are summarized in the following for a comprehensive overview by referring to related references for more details on the results.

Starting from laboratory experiences, a wide campaign of vibration tests were executed at LNEC in Lisbon on the steel frame equipped with a passive control device based on tendons in the two directions, shown in Fig. (1), by using a shaking table facility [27].

Actually tendons are particularly suitable for shearframes subject to alternate cyclic loading conditions, in order to mitigate the effects induced in the structure by random forcing actions by increasing the structure dissipative capability and stiffness.
The structural elements of the test steel frame in Lisbon were designed through an elastic analysis with the finite element program SAP-2000NL for two earthquake time history accelerations, both with peak ground acceleration of $0.5 \mathrm{~g}$ : one was a simulated earthquake according to type 1 seismic action of the Eurocode-8 [32-34]; and the other one was the $1940 \mathrm{El}$ Centro earthquake. The El Centro time history is a low frequency shake with most of its energy in the frequency below $8 \mathrm{~Hz}$, hence it is suitable to test the specimen at its natural frequency, moreover this earthquake, even if is not ideally suited to the role of the standard time history, is useful to test any shaking table up to its performance limits.

The choice of the steel sections was based on a compromise between flexibility and maximum admissible displacements during the tests, because it is necessary to have a structure with natural frequency in a useful range for experimental tests, between 6 and $20 \mathrm{~Hz}$, but with bounded displacements not exceeding the imposed limit by the actuator capacity.

So columns and beams were respectively chosen as HEB 100 and HEB 180 steel sections, while the $\mathrm{K}$ and $\mathrm{X}$ braces were chosen as HEB 100 and UPN 100 sections. For the latter case the choice was imposed to allow the cross of the braces. The steel selected is of grade S355.

Shaking table experimental investigations were executed as well at the Laboratory of the Department of Structural Engineering of the University of Naples on the Ytong and metallic blocks shown in Fig. (2), equipped with sloshing dampers prototypes Fig. (3) and placed on a shaking table. Tests executed in the presence or not of liquid tanks showed the potential of such devices in mitigating the primary model response, whose results are reported in details in [35-38].

The possibility of preventing collapses of structures moving in a rigid mode, and, in particular by a rocking mode under dynamic loading, by means of additional masses suitably tuned to the basic characters of the structure itself is a rarely treated problem, although devices based on sloshing liquids can be recognized desirable damping properties even for these type of applications.

Actually, in general, techniques devoted to increase the damping characteristics of a structure, may significantly reduce the risk of occurrence of severe damage or structural
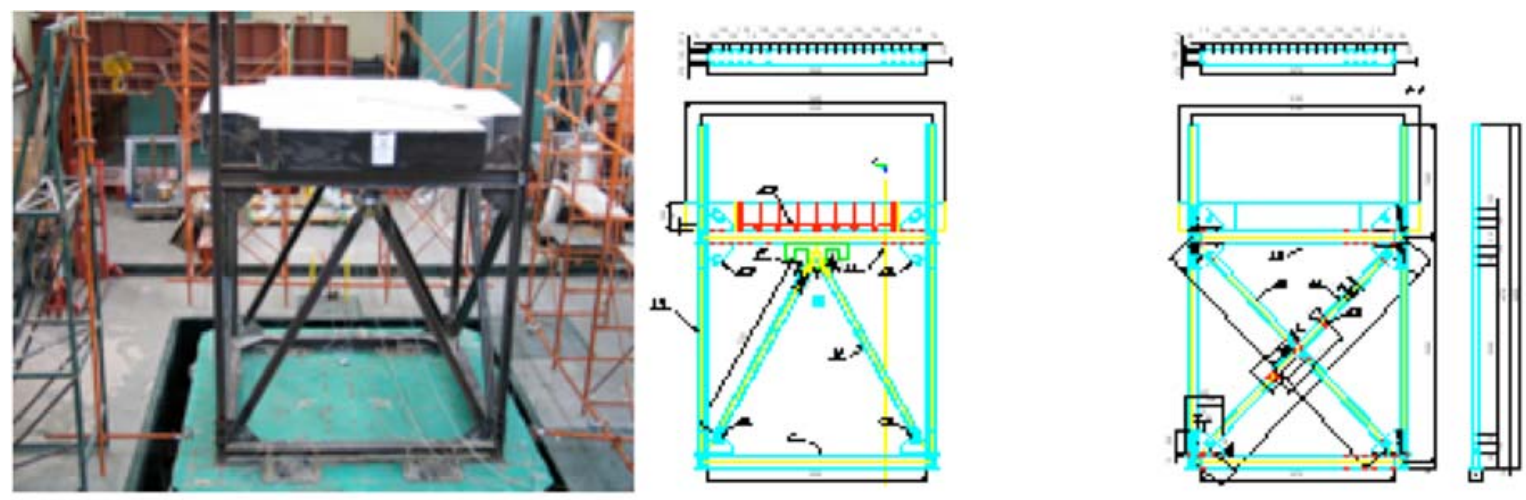

Fig. (1). The shaking table and steel braced frame with its longitudinal and transverse overviews. 

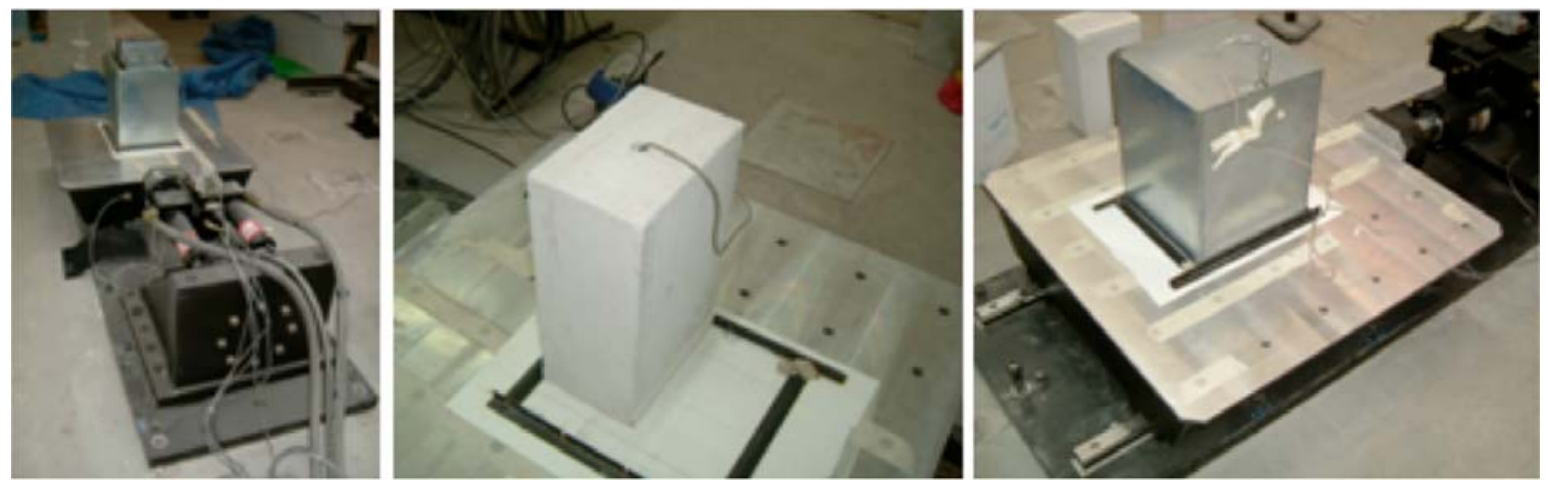

Fig. (2). The shaking table and the rigid blocks used during experiments.
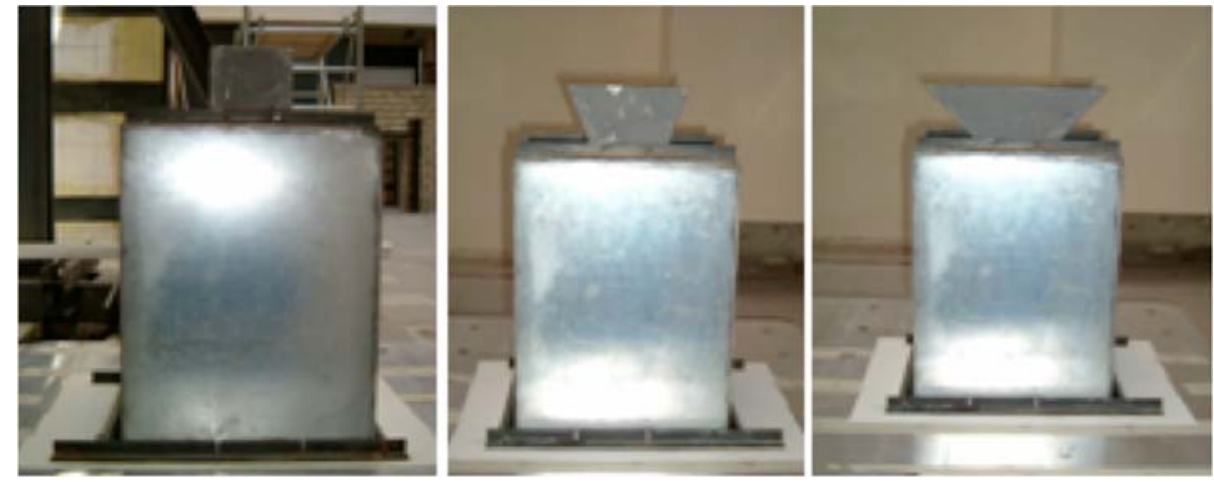

Fig. (3). Rigid structural prototypes with tanks of different shapes and liquid depths.

failures during a catastrophic event (eg. Earthquakes and hurricanes).

Serviceability considerations and other advantages, such as low cost and easiness of installation in existing structures, push toward the adoption of auxiliary damping masses to be attached to the primary structure, like Tuned Mass Dampers (TMDs), Tuned Liquid Dampers (TLDs) and Tuned Liquid Column Dampers (TLCD).

Because of its peculiar character, the evaluation of the performance, in terms of energy dissipation, of a tuned sloshing damper requires the understanding of complex fluid-structure interactions. To this end, numerical and experimental investigations on liquid tanks can provide useful information on the overall device behaviour.

The possibility of coupling liquid dampers to rigid blocks for attenuating its rocking response under dynamic excitation and/or preventing its overturning; actually the rigid block model is a pretty interesting one, since it is able to capture the essential behaviour of a wide variety of structural (or even non-structural) objects.

The tests executed in Naples first concerned the noncontrolled blocks, and were developed both on concrete (YTONG) and metallic blocks, with different dimensions placed on a unidirectional shaking table whose motion is purely transactional in the horizontal direction, with table plane geometrical dimensions in plant $1.0 \mathrm{~m} \times 1.0 \mathrm{~m}$.

Experiments were executed by varying the frequency value of the sine-wave base acceleration between $1 \mathrm{~Hz}$ and $50 \mathrm{~Hz}$ and keeping a fixed span of $5 \mathrm{~cm}$, relevant to the maximum motion of the shaking table in one direction.
As regards the concrete blocks, experiments allowed to check the great influence of even small changes in the block geometry due to small detachment of material occurring during tests and to uncertainty in the impact point.

Moreover, some small imperfections (not perfectly square shape) in the block's geometry, due to construction problems, caused the rotation of the block around its $\mathrm{z}$-axis and its moving on the surface making impossible to refer to the reported two - dimensional scheme for analyzing pure rocking of the blocks. Actually one could observe that effects of small geometrical imperfections, such as a notperfectly leveled base and a not perfectly vertical block, tend to cumulate and may become significant.

Generally speaking, peak accelerations were higher on stockier, and apparently more stable blocks, showing an unexpected effect which made the larger of the two geometrically similar blocks less stable than the smaller one.

It was also shown that the stability of a slender block subjected to a sine - wave base acceleration is much greater than the one that should be inferred from its stability against a constant horizontal force. In the light of these facts, the occasional survival of a slender structure that is apparently highly unstable is not surprising.

At the second stage, experiments were executed on uncontrolled aluminum parallelepipeds of various sizes and geometrical width/height ratios with breadth of $30 \mathrm{~cm}$., height of $40 \mathrm{~cm}$. and thickness of 10, 20 and $30 \mathrm{~cm}$ Fig. (2).

Subsequently a wide investigation campaign concerned blocks of different sizes equipped with tanks of different shapes Fig. (3), in particular rectangular or trapezoidal 

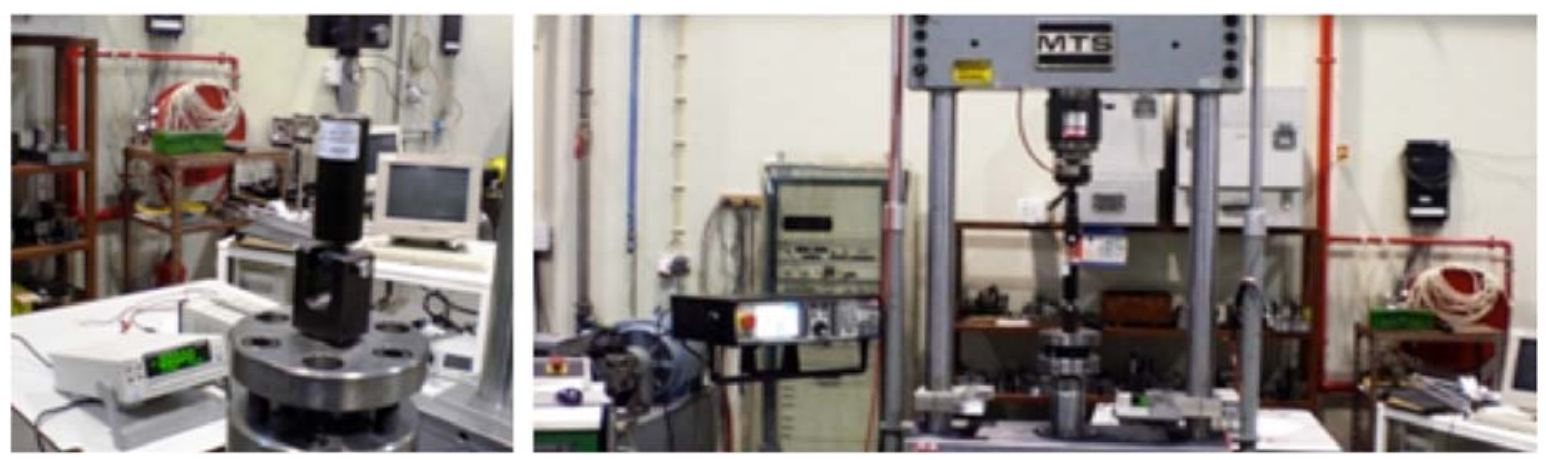

Fig. (4). Magneto-rheological damper with current supply device connected to MTS universal setup.
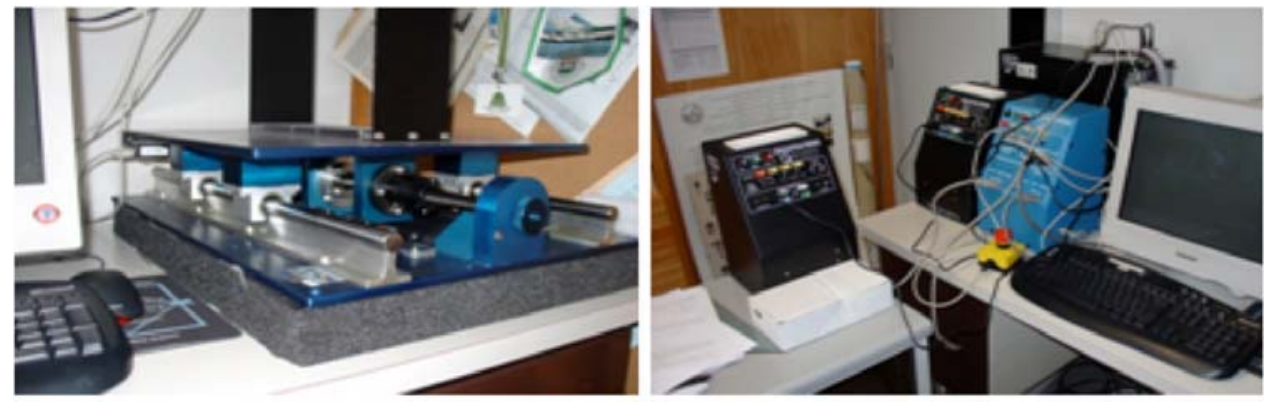

Fig. (5). Quanser shaking table II (and its controllers) at FEUP - Covicocepad Lab.

shapes with different degrees of inclination of their sides, filled in with different volumes of sloshing liquid.

In all the tested cases the benefit was found to be potentially very significant (attenuation ratio larger and even much larger than 5 in some cases) but some cases were encountered where the device increases the risk (attenuation ratio smaller than 1), which pushed towards the need of a theoretical settlement for carefully designing the device with regards to its shape and the entity of the sloshing liquid mass, keeping into account both the excitation's character and the object's inertial properties.

Some possible alternative solutions to the need of having at one's disposal reliable forecasts on the expected characters of the excitation for passive systems and to the high complexity and energy demand of active control systems are offered by the adoption of special smart materials [21-23] (shape memory alloys (SMA), electro-rheological (ER), magneto-rheological liquids (MR), etc.) for realizing semiactive devices, offering mechanical simplicity, low energy demand, skill of generating high intensity forces and, definitively, robustness.

The main characteristic of most of these materials is the reversibility of any micro-mechanical transformation they undergo after the exposition to given fields.

Smart materials can change their stiffness, shape, position, damping, frequency, viscosity and other properties in response to variations in the magnetic, electrical, stress or temperature fields.

A further distinctive and attractive feature of applications of smart materials in structural control is that actuators and sensors can be distributed and deeply integrated into the main structure, rendering much less invasive the architectural impact of insertion of control devices on existing build- ings (masonry walls and vaults might be controlled by application of smart plasters, arch bridges might be monitored by distributed layers of optical sensors and so on).

Some tests were carried out in Porto at FEUP on a LORD MR damper device by means of a MTS universal testing machine.

According to the device specifications it has a capacity to provide a peak to peak force of $2224 \mathrm{~N}$ at a velocity of 51 $\mathrm{mm} / \mathrm{s}$ with a continuous current supply of $1 \mathrm{~A}$. The MR damper was tested using the computer-controlled servo hydraulic MTS universal testing machine shown in Fig. (4). The results were automatically collected by the computercontrolled MTS equipment and stored in a desktop PC.

The variable current tests demonstrated that increasing the input current implies an increase in the force required to yield the MR fluid and a plastic-like behaviour was observed in the hysteretic loop. In the frequency dependent test it was observed that the maximum damping force was increasing with the frequency due to large plastic viscous force at higher velocity.

The subsequent campaign was developed on a scaled metallic load frame equipped with the MR dampers, placed on a QUANSER shaking table II shown in Fig. (5) as the dynamic loading actuator.

The MR damper was placed at the first floor level attached to the frame and rigidly attached to the shaking table. The structure was excited using the N-S component of the 1940 El Centro earthquake, showing that effective results may be obtained by proper tuning of the MR forcing action by means of different control algorithms.

With reference to the preservation of monumental structures, control techniques still require wide developments in 
order to respond to the major complexity of structures usually made of masonry materials, where high non- linearity is involved and problem arises in the modelling and identification of the structure.

Generally speaking, the problem of preserving architectural heritage from degradation is very complex due to the very different causes having a major impact in damaging the materials and/or the structures.

Moreover the interventions are strongly limited by the uniqueness of the work of art for which innovations materials and technologies can be used only on the premise of a deep knowledge of their behaviour in order to avoid risks of loss or irreversible damage of the heritage. To this regards one should also emphasize that a big part of constructions in historical centre, although are minor architectures and cannot be considered to have an historical interest, are made of masonry material and should be preserved as well.

The design of adequate and reliable control techniques requires deep understanding of the masonry structure, to which some of the authors have deeply contributed by developing theoretical and numerical tools under the Low or No Tension assumption of the masonry material for setting up reliable investigation methods and forecast of the structure behaviour [39-44]. To this regard one should emphasize that preservation of such structures with regards seismic excitations can be successfully obtained by adopting composite reinforcements [45] that are able to guarantee low invasiveness, reversibility, robustness, deeply increasing the performance of such structures that usually experiments critical conditions because of the activation of collapse mechanisms due to unilateral hinges formations.

\section{CONFLICT OF INTEREST}

The authors confirm that this article content has no conflicts of interest.

\section{ACKNOWLEDGEMENTS}

This work reports results from some research developed within European and National Projects, and has therefore been financially supported by the ESF within the S3T Program, by the Region Campania in Italy, the Italian Ministry of University and Research, by the Department of Civil Protection of the Italian Government through the ReLuis pool (convention No.823 signed 24/09/2009, Thematic Area 2Research Line 3-Task 1), and by the Portuguese Foundation for Science and Technology.

\section{REFERENCES}

[1] R.C. Barros, P. Belli, I. Corbi, and M. Nicoletti, "Large scale risk prevention", International Journal of Earthquake Engineering and Engineering Seismology, vol. XVIII, no. 1, pp. 10-19, 2004.

[2] A. Baratta, and I. Corbi "Epicentral distribution of seismic sources over the territory", International Journal of Advances in Engineering Software, vol. 35, no. 10-11, pp. 663-667, 2004. ISSN 09659978, DOI: 10.1016/j.advengsoft.2004.03.015.

[3] A. Baratta, and I. Corbi "Evaluation of the hazard density function at the site", International Journal of Computers \& Structures, Elsevier, vol. 83, no. 28-30, pp. 2503-2512, 2005. ISSN 0045-7949, DOI: $10.1016 / \mathrm{j} . c o m p s t r u c .2005 .03 .038$.

[4] J.M. Kelly, "A seismic base isolation: a review and bibliography", Soil Dynamics and Earthquake Engineering, vol. 5, no. 4, pp. 202216, 1986
[5] R.S. Jangid, and T.K. Datta, "Seismic behaviour of base isolated building - a state of the art review", Journal of Structures and Buildings, Proceedings of the Institution of Civil Engineers (London), vol. 110, pp. 186-203, 1995.

[6] T.T. Soong, "State-of-the-art review: active structure control in civil engineering", Engineering Structures, vol. 10, no. 2, pp. 73$84,1988$.

[7] G.W. Housner, L.A. Bergman, T.K. Caughey, A.G. Chassiakos, R.O. Claus, S.F. Masri, R.E. Skelton, T.T. Soong, B.F. Spencer Jr., and J.T.P. Yao, "Structural control: past, present and future", Journal of Engineering Mechanics, ASCE, vol. 123, no. 9, pp. 897-971, 1997.

[8] M.D. Symans, and M.C. Constantinou, "Seismic testing of a building structure with a semi-active fluid damper control system", Earthquake Engineering and Structural Dynamics, vol. 26, no. 7, pp. 59-77, 1997.

[9] T.K. Datta, "A State-of-the-art review on active control of structures", ISET Journal of Earthquake Technology, Paper No. 430, vol. 40, no. 1, pp. 1-17, 2003.

[10] F. Spencer Jr., and S. Nagarajaiah, "State of the art of structural control", Journal of Structural Engineering ASCE, vol. 129, pp. 845-856, 2003.

[11] F. Naeim, and J.M. Kelly, Design of Seismic Isolated Structures: in Theory to Practice, John Wiley \& Sons Inc.: New York - USA, 1999.

[12] T.T. Soong, and G.F. Dargush, Passive Energy Dissipation Systems in Structural Engineering, John Wiley \& Sons Ltd, Chichester England, 1999.

[13] T.T. Soong, Active Structural Control: Theory and Practice, Longman Scientific and Technical, England, U.K, 1992.

[14] H. Iemura, A. Igarashi, A. Toyooka, M. Higuchi, and O. Kouchiyama "Theoretical, numerical and experimental verification of negative stiffness dampers ", $5^{\text {th }}$ World Conference on Structural Control and Monitoring, Tokyo, 12-14 July 2010.

[15] S. Nagarajaiah, A.M. Reinhorn, M.C. Constantinou, D. Taylor, D.T.R. Pasala, and A.A.S. Sarlis, "Adaptive negative stiffness: a new structural modification approach for seismic protection ", Fifth World Conference on Structural Control and Monitoring, Tokyo, 12-14 July 2010

[16] A. Baratta, and O. Corbi, "Dynamic response and control of hysteretic structures", International Journal of Simulation Modeling Practice and Theory (SIMPAT), Elsevier Science, vol. 11, pp. 371$385, \quad 2003$. ISSN: 1569-190X, DOI: 10.1016/S1569190X(03)00058-3.

[17] R.C. Barros, and M.B. César, "Seismic behaviour of an asymmetric three-dimensional steel frame with base isolation devices", Proceedings of the Conference on Computational Structures Technology, Paper 252, Civil-Comp Press, Stirlingshire, Scotland, 2006.

[18] R.C. Barros, and M.B. César, "Influence of resistant cores location on the seismic response of a R/C 3D-frame equipped with HDRB base isolation devices". In: Topping BHV, Editor. Proceedings of the Conference on Civil Engineering Computing. Paper 199, CivilComp Press, Stirlingshire, Scotland, 2007.

[19] A. Baratta, and I. Corbi, "Optimal design of base-isolators in multistorey buildings". International Journal of Computers \& Structures, Elsevier, vol. 82, no. 23-26, pp. 2199-2209, 2004. ISSN: 00457949 , DOI: 10.1016/j.compstruc.2004.03.061.

[20] E. Figueiredo, and R.C. Barros. "An Insight on the Influence of Damping in Seismic Isolation", In: Topping BHV, Editor. Proceedings of the Conference on Civil Engineering Computing. CivilComp Press, Paper 201, Civil-Comp Press, Stirlingshire, Scotland, 2007.

[21] S.J. Dyke, B.F. Spencer, M.K. Sain, and J.D. Carlson. "Modeling and control of magnetorheological dampers for seismic response reduction", Journal of Smart Materials and Structures, vol. 5, pp. 565-575, 1996.

[22] L.M. Jansen, and S.J. Dyke. "Semi-active control strategies for MR dampers: A comparative study". ASCE Journal of Engineering Mechanics, vol. 126, no. 8, pp. 795-803, 1999.

[23] Y. Chae, J.M. Ricles, R. Sause, B. Dong, C. Chen, R.E. Christenson, S.J. Dyke, A. Agrawal, and B.F. Spencer, "Experimental studies on control strategies for steel frames with MR dampers for earthquake hazard reduction ", $5^{\text {th }}$ World Conference on Structural Control and Monitoring, Tokyo, 12-14 July 2010.

[24] A. Baratta, and O. Corbi, On the dynamic behaviour of elasticplastic structures equipped with pseudoelastic SMA reinforce- 
ments", Journal of Computational Materials Science, vol. 25, no. 1-2, pp. 1-13, 2002. ISSN: 09270256, DOI: 10.1016/S09270256(02)00245-8.

[25] O. Corbi, "Shape Memory Alloys and Their Application in Structural Oscillations Attenuation", International Journal of Simulation Modeling Practice and Theory (SIMPAT), Elsevier Science. vol. 11, pp. 387-402, 2003. E155276 - ISSN: 1569-190X. Doi: 10.1016/S1569-190X(03)00057-1.

[26] C. Kang-Min, C. Sang-Won, J. Hyung-Jo, and L. In-Won, "Semiactive fuzzy control for seismic response reduction using magnetorheological dampers", Journal of Earthquake Engineering and Structural Dynamics, vol. 33, pp. 723-736, 2004.

[27] A. Kareem, "Next generation of tuned liquid dampers", Proceedings of the $1^{\text {st }}$ World Conference on Structural Control, vol. 3, pp. 19-28, Los Angeles, 1994.

[28] D. Foti, and R. Nobile, "Optimum Design of a New Hysteretic Dissipater", chapt 12 in Design Optimization of Active and Passive Structural Control Systems by N.D. Lagaros, V. Plevris, C.C. Mitropoulou, pp. 274-299; Ed. IGC Global USA, Hershey PA 17033 USA. DOI: 10.4018/978-1-4666-2029-2, ISBN 978-1-4666-20292, 2012.

[29] D. Foti, L. M. Bozzo, and F. Lopez-Almansa, "Numerical efficiency assessment of energy dissipators for seismic protection of buildings", Earthquake Engineering and Structural Dynamics, Wiley \& Sons, Ltd., Chichester, UK, vol. 27, pp. 543-556, 1998. ISSN: 0098-8847.

[30] A. Baratta, I. Corbi, and S. Coppari, "A method for the evaluation of the seismic vulnerability of fortified structures", Final Conference on COST Action C26: Urban Habitat Constructions under Catastrophic Events;Naples, Code89987, pp. 547-552, 2010. ISBN: 978-041560685-1.

[31] A. Baratta, I. Corbi, O. Corbi, and D. Rinaldis, "Experimental survey on seismic response of masonry models", Proceedings of the 6th International Conference on Structural Analysis of Historic Constructions: Preserving Safety and Significance, vol. 2, pp. 799807, 2008. ISBN: 0415468728; 978-041546872-5.

[32] R. Bairrão, O. Bursi, P. Carydis, G. Magonette, H. Mouzakis, D. Tirelli, and M. Williams, "Benchmark Testing and Performance Comparison of Shaking Tables and Reaction Walls", Proceedings of $13^{\text {th }}$ World Conference on Earthquake Engineering, Paper 441, 2004, Vancouver, Canada.

[33] Industrial Application of Shaking Tables and Reaction Walls, NEFOREEE Project, 2004, University of Trento, Italy.

[34] prEN 1998-1. Eurocode 8: Design of Structures for Earthquake Resistance. Part 1: general rules, seismic actions and rules for buildings; CEN - European Committee for Standardization, 2002, Brussels, Belgium.

[35] O. Corbi, "Efficacy of liquid dampers for dynamic attenuation purposes", Journal of WSEAS Transactions on Systems, vol. 5, no. 7, pp. 1702-1711, 2006. ISSN: 1109-2777.
[36] A. Baratta, and O. Corbi "Analysis of the dynamics of rigid blocks using the theory of distributions", Advances in engineering Software, vol. 44, no. 1, pp. 15-25, 2012. ISSN: 09659978CODEN, DOI: 10.1016/j.advengsoft.2011.07.008.

[37] A. Baratta, I. Corbi, and O. Corbi, "Rocking Motion of Rigid Blocks and their Coupling with Tuned Sloshing Dampers", in B.H.V. Topping, L.F. Costa Neves, R.C. Barros, (Eds). In: Proceedings of the Twelfth International Conference on Civil, Structural and Environmental Engineering Computing, Civil-Comp Press, Stirlingshire, UK, Paper 175, 2009. ISBN: 978-1-9050-8832-4, DOI:10.4203/ccp.91.175.

[38] A. Baratta, and I. Corbi "Dynamics of rigid bodies under pure rocking", WSEAS Transactions on Systems, vol. 5, no. 7, pp. 17111716, 2006. ISSN: 1109-2777.

[39] A. Baratta, I. Corbi and O. Corbi, "Stress analysis of masonry structures: Arches, walls and vaults", Proceedings of the $6^{\text {th }}$ International Conference on Structural Analysis of Historic Construction: Preserving Safety and Significance, SAHC08; Bath; 2-4 July 2008; vol. 1, pp. 321-329, 2008. ISBN: 978-0-415-46872-5.

[40] A.Baratta, and O. Corbi, "An approach to masonry structural analysis by the no- tension assumption-Part I: material modeling, theoretical setup, and closed form solutions", Applied Mechanics Reviews, ASME, vol. 63, no. 4, pp. 040802-1/17, 2010. ISSN 00036900, DOI:10.1115/1.4002790.

[41] A. Baratta, and O. Corbi, "An approach to masonry structural analysis by the no-tension assumption-Part II: load singularities, numerical implementation and applications", American Society of Mechanical Engineers, ASME International vol. 63, no. 4, pp. 040803-1/21, 2010. doi:10.1115/1.4002791, ISSN 0003-6900 (print) 0003-6900 (online)

[42] A. Baratta, and O. Corbi, "On the equilibrium and admissibility coupling in NT vaults of general shape", International Journal of Solids and Structures, vol. 47, no. 17, pp. 2276-2284, 2010. ISSN: 0020-7683. DOI: 10.1016/j.ijsolstr.2010.02.024.

[43] A. Baratta, and O. Corbi, "On variational approaches in NRT continua", International Journal of Solids and Structures, vol. 42, pp. 5307-5321, 2005. ISSN: 0020-7683. DOI:10.1016/j.ijsolstr.2005.03.075.

[44] A. Baratta and I. Corbi, "On the statics of masonry helical staircases", in B.H.V. Topping, Y. Tsompanakis, (Editors), Proceedings of the $13^{\text {th }}$ International Conference on Civil, Structural and Environmental Engineering Computing, Civil-Comp Press, Stirlingshire, UK, Crete; Paper 59, 6 -9 September 2011. ISBN: 978190508845-4, DOI:10.4203/ccp.96.59.

[45] A. Baratta, and O. Corbi, "Stress analysis of masonry vaults and static efficacy of FRP repairs", International Journal of Solids and Structures, vol. 44, no. 24, pp. 8028-8056, 2007. ISSN: 0020-7683.

Received: October 22, 2012

Revised: November 02, 2012

Accepted: November 04, 2012

() Baratta et al.; Licensee Bentham Open.

This is an open access article licensed under the terms of the Creative Commons Attribution Non-Commercial License (http://creativecommons.org/licenses/by-nc/3.0/) which permits unrestricted, non-commercial use, distribution and reproduction in any medium, provided the work is properly cited. 